\title{
Raising awareness among health students about aging changes
}

\begin{abstract}
Background: The increase in the elderly population and life expectancy has led health professionals to seek qualification and improve their knowledge, skills, and attitudes to provide care to this population group.

Strategies: Simulation is used as a learning strategy in the care of older people to make health professionals aware of the changes in the aging process, by means of seven stages: learner's previous knowledge, learning objectives, theoretical foundation, checklist, setting development, debriefing, and assessment.
\end{abstract}

Conclusion: Health professionals must apprehend theoretical knowledge in the construction of care and have the opportunity to use simulation in this experience, enabling to transfer knowledge to their work environment with older people.

Keywords: geriatrics, simulation, health personnel
Volume 3 Issue I - 2018

\author{
Rosalina Aparecida Partezani Rodrigues,' \\ Luciana Kusumota,' Jack Roberto Silva \\ Fhon, ${ }^{2}$ Alexandre de Assis Bueno ${ }^{2}$ \\ 'Professor, College of Nursing of Ribeirão Preto, University of \\ São Paulo, Brazil \\ ${ }^{2}$ College of Nursing of Ribeirão Preto, University of São Paulo, \\ Brazil
}

\begin{abstract}
Correspondence: Rosalina Aparecida Partezani Rodrigues, Professor, College of Nursing of Ribeirão Preto, University of São Paulo, PAHO/WHO Collaborating Center for Nursing Research Development, Brazil, Email rosalinaprodrigues@gmail.com
\end{abstract}

Received: December 12, 2016 | Published: January 09, 2018

\section{Introduction}

Globalization has had repercussions on the daily lives of individuals, including on health. The ease with which people cross borders has contributed to these changes occurring in an accelerated and constant way. In this new context, health workers face daily challenges due to various transitions, such as demographic and epidemiological ${ }^{1}$ which has required students to assume a proactive attitude, with value given to the coordination of their knowledge, skills, and attitudes, where assertiveness is the result of any decision-making process. In light of this prerogative, active methodologies started being used in the training and professional enhancement processes of students, in order to equip them with a critical-reflective outlook Simulationbased learning has been one of the strategies used the most in the training of these professionals for various reasons since, for example, it interconnects distinct processes involved in decision making and the coordination of teamwork, which are fundamental aspects in the dynamics of health actions. ${ }^{2}$
This awareness-raising activity uses the construction of a theoretical-practical roadmap developed by Fabri et al. ${ }^{3}$ as shown in Table 1 below:

The use of clinical simulations to train health students in the preparation of gerontological and geriatric care is conducive to the learner's development at three levels. ${ }^{2,4}$ The first is relational: elaboration of the scenario leads to identification of the subjects involved in the care construction process and definition of the roles played by each one of these actors. This level is fundamental in the care process, since it involves not only the reception of the elderly person, but also all the aspects related to the care humanization. Visualizing the actors involved and experiencing firsthand the role of each one helps create inclusive, humanized care, aimed at greater autonomy. At this level, it is also possible to identify the essential support networks for a healthy aging process. The second level is related to care and, at the third level, students have the opportunity to develop work with light/hard technology and greater or less complexity, depending on the level of care provided.

Table I Stages of the roadmap for preparing the scenario, according to Fabri et al.

\author{
Knowledge prior to the scenario \\ Student's prior knowledge Key aspects of already existing relevant content in the student's cognitive structure. \\ Learning objectives \\ Desired results for the student. \\ Theoretical foundation \\ Use of the best levels of evidence available in the literature. \\ Preparation of the Scenario \\ Checklist Identifying priority actions for carrying out the case and guiding the observation. \\ Final Components of the Scenario \\ Scenario development \\ It must be contextualized based on the evolution of the clinical case, prior history and current situation. \\ Debriefing \\ Clarification stage, which is planned and directed toward promoting reflective and critical thought. \\ Evaluation \\ It should be formative, deliberated and continuous.
}


In view of the technological evolution of the medical field in recent years, providing an opportunity for students to have contact with and handle this technology during their training process is essential for them to appropriate the technological resources available for ensuring the most comprehensive care possible. In this aspect, simulation provides a critical-reflective environment for improving the technique, in order to enhance the quality of the care process and minimize the risks inherent to it, since it enables students to develop competencies, skills, and attitudes. It also allows them to acquire confidence and capability in managing the care of those in senescence and senility processes ${ }^{5}$ without exposure of the elderly person and to enable a continuous assessment process aimed at improving the care given. Since they receive more training, this type of activity allows students to carry out their tasks in less time and with fewer risks which is beneficial to elderly patients.

Since the aging process is physiological, irreversible and can cause

Table 2 Simulation to raise students' awareness to the experience of the aging process

Simulation-based learning: Stages

Staffing required: Educators: Physicians and nurses physical and cognitive limitations, elderly people are more liable to different adverse indicators in the health process. Therefore, the selection of an educational strategy is a critical aspect.

In light of the above, the goal of the simulation in question is to provide opportunities for health students to understand better this process and the limitations of aging through an active learning strategy, based on the use of an aging simulator. In this case, in order to improve the teaching and training of health students in simulation classes, the Aged Simulation Set ${ }^{6}$ mannequin will be used. The goal of this educational tool is to demonstrate how changes take place in the aging process. During the activity, the students experience musculoskeletal (elbow and knee joint restrictions), visual (loss of peripheral vision), hearing (reduced sound) and touch-related limitations that frequently occur in elderly people and create difficulties for satisfying certain basic human needs (Table 2).

Equipment required: Low-fidelity simulator; Device for measuring blood pressure and a stethoscope;

$3 \mathrm{~m}$ of yellow tape for measuring gait

Case description: D.S., 80 years old, female, married for 50 years to R.T., 84 years old. They have five children and live alone. She reported two falls in the last 12 months. She has hypertension and osteoporosis and uses various medications. She lost approximately four kilos and her body mass decreased, resulting in reduced functional capacity. She needs help to get out of bed and carry out her normal daily activities. Some of her sensory organs have also been affected. Her walking speed has decreased and her legs are weak.

Simulator Operation: D.S. will be sitting in a chair, with pain in her knees. In the activity, she will be asked to walk, but will need help to get up. Her gait will be slow and unstable. Blood pressure $=140 \times 100$ and she has reduced vision and hearing.

Target audience: health students intending to study geriatrics. A student will enact the role of an elderly person.

Manikin preparation:The Aged Simulation Set; bed, cane, chair, table, yellow tape on the ground, blood pressure device.

Blood pressure assessment.

\section{Debriefing}

The educators will request the following:

I. The actor will verbalize the positive aspects of the experience and points to be improved, as well as discuss the perception of the experience as an elderly person.

I. The actor will verbalize the positive aspects of the experience and points to be improved, as well as discuss the perception of the experience as a health professional.

Content to be explored in the teaching-learning process: physiological aging with an emphasis on musculoskeletal/gait and balance changes, as well as changes in sensory organs (hearing, sight, Taste/swallowing and touch). Greater fall risk: intrinsic and extrinsic factors.

Evaluation: Post-test after simulation and accounts of the experience during the simulation.

Teaching how to care for elderly people stretches across different cultural contexts and health dimensions and, consequently, needs to be based on understanding the meaning of aging, the stages, and the easy and difficult aspects inherent to this process as a whole, but with individual meanings.

Although health students base the building of care of elderly people on theoretical knowledge, they have not yet experienced this process personally, which makes the use of clinical simulation an enriching strategy in the learning process.

Therefore, this activity seeks to provide health students with different experiences that enable the expansion of theoretical teachings and the application of this knowledge to the workplace, which is conducive to their praxis and the approximation of responses to the health-disease process of elderly people. ${ }^{7}$

\section{Acknowledgements}

None.

\section{Conflict of interest}

Authors declare that there are no conflicts of interest. 


\section{References}

1. Fortes PAC, Ribeiro H. Global Health in globalization times. Saude soc. 2014;23(2):366-375.

2. Dourado ASS, Giannella TR. Simulation-based learning in continuing medical education: analysis of student and teacher perceptions of a Hospital in Rio de Janeiro. Rev bras educ med. 2014;38(4):460-469.

3. Fabri RP, Mazzo A, Martíns JCA, et al. Development of a theoricalpractical script for clinical simulation. Rev Esc Enferm USP. 2017;51:e0318.
4. Abreu AG, Freitas JS, Berte M, et al. The useof realistic simulation as teaching-learning methodology for nursing staff in a child-adolescent hospital: experience report. Cienc saude. 7(3): 162-166.

5. Joint Royal Colleges of Physicians Training Board. Specialty training curriculum for geriatric medicine curriculum. London, UK; 2010.

6. http://www.kokenmpc.co.jp/english/products/life_simulation_models/ nursing_education/lm-060/index.html

7. Chakravant B, Haar E, Bhat SS, et al. Simulation in medical school education: review for emergency medicine. West $J$ Emerg Med. 2011;12(4):461-466. 